Ideología, discursos morales y violencia de género. La mirada del "otro" sobre nuestros cuerpos

Fabiana Parra

Question, Vol. 1, N.ำ57, e019, enero-marzo 2018. ISSN 1669-6581

http://perio.unlp.edu.ar/ojs/index.php/question/article/view/4396

FPyCS | Universidad Nacional de La Plata

La Plata | Buenos Aires | Argentina

Recibido: 12-10-2017 Aceptado: 17-11-2017

Cita sugerida: Parra, F. (2018). Ideología, discursos morales y violencia de género. La mirada del "otro" sobre nuestros cuerpos. Question, 1(57), e019. doi: https://doi.org/10.24215/16696581e019

\title{
Ideología, discursos morales y violencia de género. La mirada del "otro" sobre nuestros cuerpos
}

\author{
Ideology, moral discourses and gender violence. The look of the "other" \\ over our bodies
}

Fabiana Parra

Instituto de Investigaciones en Humanidades y Ciencias Sociales;

Universidad Nacional de La Plata/ Consejo Nacional de Investigaciones Científicas y Técnicas (Argentina) fabianaparra00@gmail.com

\section{Resumen}

Estas líneas tienen como motivación principal explorar los discursos morales que, en contextos de avanzada neoliberal y neoconservadora como es el latinoamericano, apuntan a reactivar dicotomías jerárquicas -tales como cuerpo/alma; naturaleza/cultura; pasión/razón; materia/pensamiento- propias de la lógica occidental moderna. Bajo la cual "lo corporal" es homologado a "lo más bajo", por tanto debían ser suprimidos, y superados. 
Tal estatuto de inferioridad y de aniquilamiento es el mismo que recorre los discursos morales que tienen como efecto garantizar tanto la sujeción de las mujeres a determinados lugares sociales, así como evitar el control de éstas sobre sus propios cuerpos. Siendo su reverso: la legitimación del sujeto único de la universalidad: el sujeto propietario.

Este trabajo propone explorar estas tensiones, sus supuestos y sus efectos sobre los sujetos más vulnerables. Con el objetivo principal de abonar argumentos para combatir la violencia estructurante y estructural contra la alteridad, propia de la modernidad colonial y capitalista.

Palabras claves: ideología; discurso; sujeto; cuerpo; violencia.

\section{Abstract}

These lines have as the main aim explore the moral discourses that, in neoliberal and neoconservative advanced context as Latin-American one, point to reactivate hierarchical dichotomys like -body/soul, nature/culture, passion/reason, substance/thought- typic of a modern logic under which "the corporal" is homologated to "the poorest" and therefore have to be suppressed and overcomed.

The inferior and annihilation status is the same that goes across the moral discourses that have as effect guaranteed the fastening of women to certain social places, as well as, the women's control of their own bodies. Being the reverse: the legitimation of the unique subject of the universality: the owner subject.

The purpose of this work is explore the tensions, their assumptions and their effects on the most vulnerable subjects to contribute with arguments to fight to structurant and structural violence against the otherness, distinctive of the colonial and capitalist modernity.

Keywords: ideology; discourse; subject; body; violence.

La Modernidad occidental se estructura sobre una lógica binaria, dicotómica y jerárquica a partir de la cual se fundamenta la negación y la dominación del "otro" (1). Esta Modernidad es la que emerge al calor de lo que se ha llamado "el siglo de los genios" -que nuclea entre otros a Copérnico, Bacon, Kepler, Galileo, Shakespeare, Descartes- como testigos del nacimiento de la ciencia moderna y de un espíritu racionalista que coloca al cogito en el centro del conocimiento. Tal antropocentrismo se caracteriza por oponer la Razón al Cuerpo, desatando un enfrentamiento entre "lo mejor" y "lo más bajo". La siguiente cita ilustra de manera impecable lo anterior: 


\begin{abstract}
El nuevo cimiento del conocimiento producido por el cartesianismo ya no es el Dios cristiano, sino este nuevo «yo». Si bien Descartes nunca define quién es este «yo», es claro que en su filosofía ese «yo» reemplaza al Dios de la cristiandad como nuevo fundamento del conocimiento y sus atributos constituyen una secularización de los atributos del Dios cristiano. Para Descartes, el «yo» puede producir un conocimiento que es «verdadero» más allá del tiempo y el espacio, «universal» en el sentido de que no está condicionado por ninguna particularidad, y «objetivo» entendido como equivalente a «neutralidad». En fin, la visión cartesiana argumenta que este «yo» puede producir un conocimiento desde el «ojo de Dios». Para hacer la aseveración de un «yo» que produce conocimiento equivalente a la visión del ojo divino (Dios), Descartes plantea dos argumentos principales: uno ontológico y el otro epistemológico. Ambos argumentos constituyen la condición de posibilidad para la afirmación de que este «yo» puede producir un conocimiento que es equivalente al «ojo de Dios». El primer argumento es el dualismo ontológico. Descartes afirma que la mente es de una sustancia muy distinta al cuerpo. Esto permite a la mente estar indeterminada e incondicionada por el cuerpo. De esta forma, Descartes puede aseverar que la mente es similar al Dios cristiano que flotando en el cielo, indeterminado por cualquier cosa terrestre, puede producir un conocimiento equivalente al «ojo de Dios». La universalidad equivale aquí a la universalidad del Dios cristiano en el sentido de que no está determinada por particularidad alguna y está más allá de cualquier condicionamiento o existencia particular en el mundo (Grosfoguel, 2013: 37-38).
\end{abstract}

En el marco de la filosofía cartesiana- mecanicista, dualista y solipsista- paradigmática de la Modernidad occidental, el estudio en torno al funcionamiento de la mecánica del cuerpo -cuyos elementos constitutivos, desde la circulación de la sangre hasta la dinámica del habla son clasificados minuciosamente- adquiere una importancia sin igual.

Tal es así que para Descartes -el gran filósofo moderno- existe una identidad entre el cuerpo y la naturaleza dado que están compuestos por los mismos elementos y obedecen a las mismas leyes físicas. A partir de la identificación se construye una nueva ontología, como da cuenta Silvia Federici (2010) "entre la esencia de la humanidad y sus condiciones accidentales, el cuerpo está divorciado de la persona, está literalmente deshumanizado. No soy este cuerpo" (p. 225).

Bajo estos cánones modernos, el cuerpo es concebido puramente como materia inertecompletamente separada de la actividad racional- y descrito por analogía con la máquina. De allí que en este escenario los intelectuales se preguntaran: “¿Puede el cuerpo pensar?”, “No, sin duda, pues todas las modificaciones de tal extensión consisten sólo en ciertas relaciones de distancia (...)" (Popkins, 1996: 280).

Si tiramos de este hilo, podemos llegar hasta la conceptualización del valor del trabajo en el Acto I de La tempestad de Shakespeare en el que se hace referencia al cuerpo como productor 
de la fuerza de trabajo. Pues el trabajo, más que cualquier recurso natural, se convierte en el periodo de transición del feudalismo al capitalismo en la fuente principal de acumulación. Lo cual cobra total sentido si atendemos al hecho de que en la "era de la Razón" la burguesía emergente intentó adecuar las clases subordinadas a las necesidades de desarrollo de la economía capitalista, creando un nuevo tipo de individuo.

Es más, ha sido bajo la pretensión de crear un sujeto capitalista que la burguesía entabló una batalla contra el cuerpo que se convirtió en su impronta histórica. En la reforma del cuerpo que está en el corazón de la ética burguesa de Max Weber -por ejemplo- se manifiesta que el capitalismo hace de la adquisición "el objetivo final de la vida" (1958: 53) en lugar de tratarla como medio para satisfacer las necesidades humanas. Lo que conlleva grandes efectos nocivos para los sujetos. Primordialmente para los otros, los vulnerables, los marginales; pero para la humanidad en general, ya que como se ha señalado innumerables veces, no existe verdadera libertad mientras existan oprimidos, por más que la plenitud sea un imposible. El tipo de vida en las sociedades capitalistas es una vida alienada ya que, por una parte, los poseedores tienen una aparente existencia humana, mientras que los desposeídos tienen una vida humana indigna (Pavón Cuellar, 2014: 233-239).

Que dependamos del consumo para realizarnos humanamente tiene como reverso que perdamos gradualmente las formas espontáneas de disfrutar de la vida, y que las cosas nos interesen en la medida que podamos poseerlas (2). Pero además, tanto la pérdida como la superación de nuestro "estado natural" se vincula estrechamente con el interés del proyecto capitalista de "romper las barreras de la naturaleza" al extender el día de trabajo todo lo posible, tal como advierte Marx en los Manuscritos de 1844 en su análisis en torno a la enajenación.

Así las cosas, para que el proyecto político capitalista fuese instaurado era necesario erradicar del proletariado cualquier comportamiento que no condujera a la imposición de una disciplina de trabajo más estricta. Es por ello que en la filosofía mecanicista se percibe un nuevo espíritu burgués que "calcula, clasifica, hace distinciones y degrada al cuerpo sólo para racionalizar sus facultades, lo que apunta no sólo a intensificar su sujeción, sino a maximizar su utilidad social (Federici, 2010: 224).

Cabe señalar que aunque ni Hobbes ni Descartes dedicaron mucha atención a los asuntos económicos "sus contribuciones acerca de la naturaleza humana -en las que se representa al cuerpo como algo vacío y mecánico- hicieron a la aparición de una ciencia capitalista del trabajo" (Ídem). Lo cual explica que el cuerpo, desde entonces, constituyera parte central de las políticas públicas porque aparecía no sólo como una bestia inerte ante los estímulos del trabajo, sino como un recipiente de fuerza de trabajo, un medio de producción: la máquina de trabajo primaria. 
Es por ello que en las estrategias que adoptó el estado hacia el cuerpo encontramos mucha violencia pero también mucho interés. Al decir de Michael Foucault el "disciplinamiento del cuerpo" puede ser pensado como el intento del estado en transformar las potencias del individuo en fuerzas de trabajo. Es por ello que el estudio de los movimientos y propiedades del cuerpo se convirtió en el punto de partida para buena parte de la especulación teórica de la época, ya sea utilizándolo como Descartes para afirmar la inmortalidad del alma; o para investigar, como Hobbes, las premisas de la gobernabilidad social.

Ahora bien, si en este periodo de instauración capitalista el estatuto del cuerpo no es el del margen sino que adquiere una centralidad indiscutible, ¿qué es lo que ocurre con el cuerpo de los sujetos femeninos en tanto alteridad? ¿Cómo se reconfigura el cuerpo al ser considerado como espacio de saber, como condensador físico de experiencias y de memorias ancestrales? ¿Cómo se vincula esta reconceptualización con el hecho concreto de que las brujas sean perseguidas y asesinadas brutalmente por la Inquisición? ¿Qué relación guarda esta matanza con el surgimiento del nuevo orden capitalista? ¿Existe aún hoy una relación entre la concepción moderna del cuerpo separado del alma y la violencia contra las mujeres? Podríamos seguir formulando interrogantes pero por lo pronto nos interesa enfatizar la contundencia del argumento de Federici que revela que las mujeres homologadas a la naturaleza, y la identificación de éstas con la corporalidad (2010: 27) -a través de los discursos morales de la época que representaba a las mujeres como carentes de racionalidad: "excesivamente emocionales", "lujuriosas" e "incapaces de manejarse por sí mismas"- tuvo como efecto que éstas fueran puestas necesariamente bajo el control masculino y del Estado.

Ciertamente, la denigración de las mujeres a través de las construcciones discursivas de la época las exponía como "poco razonables, vanidosas, salvajes, despilfarradoras, regañonas, bestialmente sexuales, brujas, y hechiceras, entre otras cosas" (Ibídem: 180). En Rey Lear (1606) de William Shakespeare se lee: "De cintura para abajo son centauros, aunque sean mujeres arriba. Hasta el talle gobiernan los dioses; hacia abajo los demonios. Ahí está el infierno, las tinieblas, el pozo sulfúreo, ardiendo, quemando; peste podredumbre" (Federici, 2010: 259). Tales representaciones fueron creando las condiciones para que las mujeres fueran privadas del control de sus cuerpos y de sus decisiones en todo lo vinculado a sus proyectos de vida. Uno de los derechos que perdieron fue el de poder realizar actividades económicas por su cuenta, lo que habilitó su sujeción a los hombres perdiendo así, tanto poder social como político y económico.

Lo sintomático es que cuando se instaura el capitalismo, el discurso sobre éstas cambia. $\mathrm{Si}$ antes estas eran consideradas como irracionales y bestiales, a partir de entonces se las describe como "obedientes", "sumisas", "capaces de apaciguar a los hombres", etc. Poniendo de manifiesto con total vigor que las mujeres pudieron ser "domesticadas" gracias a un proceso de degradación social. 
De manera similar ocurre con la demonización de los colonizados, cuya supuesta naturaleza bestial y animal es la que sirve para justificar el trabajo forzado que estos debían realizar, y la violencia extrema que se desató sobre sus cuerpos, y que explora el análisis de Aníbal Quijano (2002). Para este último, la modernidad y la colonialidad permiten ver el encastre entre la racialización total de la división del trabajo y la producción de conocimiento, que inferioriza y suprime al "otro", dando lugar a la colonialidad del poder, un poder capitalista, eurocentrado y global que surge a comienzos del siglo XVII y que se imbrica con la idea de "raza" (3).

Pero lo que no se puede ver, efecto de una ceguera epistemológica como advierte María Lugones (2011), es que la dicotomía fundamental de la colonialidad moderna "es la distinción entre lo humano y lo no-humano" (p. 130) a partir de la cual los negros e indios- los no humanos- eran considerados como seres sin género: "en tanto bestias se los trató como totalmente accesibles sexualmente por el hombre y sexualmente peligrosos para la mujer" (Ídem). Dado que en el sistema moderno colonial, el género sólo aplica para quienes pertenecen al canon de "lo humano", los blancos; los colonizados tendrán el estatuto de machos "no-humanos". Mientras que las colonizadas se constituyen en alteridad radical son "lo no humano de lo no macho". Lo cual habilitó que sufrieran todo tipo de aberraciones mediante la violencia extrema:

\footnotetext{
La misión civilizadora colonial era la máscara eufemística del acceso brutal a los cuerpos de las personas a través de una explotación inimaginable de violaciones sexuales, del control de la reproducción y el terror sistemático (alimentando perros con personas vivas o haciendo bolsas y sombreros de las vaginas de mujeres indígenas brutalmente asesinadas, por ejemplo) (Lugones, 2011: 108).
}

Llegados a este punto, cabe señalar que si bien consideramos acertado y sumamente valioso el análisis de Lugones al postular que la modernidad organiza el mundo ontológicamente en términos de categorías homogéneas, atómicas y separadas; resulta importante que los posicionamientos feministas críticos y contra hegemónicos contribuyan al desarrollo de un análisis de la colonialidad y del racismo -ya no como fenómeno sino como episteme intrínseca a la modernidad. Desde tales posicionamientos se realiza una lectura sintomática (4) de los silencios y ausencias que invisibilizan la diferencia. Lo cual habilita a comprender el entramado complejo de los entrecruzamientos entre etnia/raza, clase y género/sexo que opera de manera diversa en los sujetos de acuerdo con sus condiciones reales de existencia, para decirlo en términos de una perspectiva materialista como la de Althusser.

Precisamente, es a partir del reconocimiento de la multiplicidad de opresiones -que se imbrican y se combinan- en los sujetos que debemos comenzar a sospechar para luego abandonar la 
pretensión de universalidad que subyace bajo la categoría "mujeres" propuesta por el feminismo eurocentrado. Una categoría estática y monolítica que invisibiliza la otredad y que reactiva la concepción moderna de un sujeto universal cuyo cuerpo está separado del alma y en cuya unidad orgánica se "imprimen" las determinaciones como atributos de un cuerpo, superficie vacía.

De allí que podamos considerar como una alternativa superadora la propuesta que se realiza desde epistemologías "otras" al postular la naturaleza corporizada de todo pensamiento (Sciortino, 2012). Valiéndose para ello de los saberes situados y destacando la importancia de la interseccionalidad y la combinatoria para poder comprender la profunda imbricación entre relaciones de poder vinculadas a la geopolítica, la cultura, la elección sexual, la pertenencia de clase y étnica, que componen el entramado complejo de las formaciones sociales (5).

\section{Cuerpos "rebeldes" que deben ser domesticados}

Las mujeres constituidas en alteridad radical serán disciplinadas mediante formas específicas de control y con la máxima violencia. Es lo que se manifiesta al considerar, por ejemplo, la radicalización de los castigos en contextos particularmente hostiles como las detenidas en centros clandestinos de detención en la última dictadura cívico-militar argentina. Por lo cual se puede afirmar que la violencia de género se conforma histórica y sistemáticamente como una estrategia de aniquilamiento de los sujetos femeninos (6).

Siguiendo la perspectiva inclusiva e interseccional de Federici al analizar el entrecruzamiento entre mujer, cuerpo y acumulación originaria- se puede afirmar que la persecución de miles de brujas en el medioevo ha sido un acontecimiento fundamental para el advenimiento del capitalismo, y el establecimiento del control del Estado sobre los cuerpos de las mujeresreproductoras de fuerza de trabajo.

La acumulación originaria entendida como precondición de la riqueza, requirió la sumisión de las mujeres a la reproducción de la fuerza de trabajo; más precisamente, requirió que estas ocuparan el lugar de "sirvientas" de la fuerza de trabajo masculina. De esta manera, el trabajo femenino se convirtió en un recurso natural disponible: las mujeres se constituyeron en bienes comunes y fueron obligadas a procrear y a realizar tareas domésticas que no categorizaban como trabajo asalariado. Ha sido justamente el ocultamiento de esta explotación lo que ha permitido al capitalismo acrecentar sus ganancias y acumular trabajo femenino "esclavo" a partir del marco legal de la nueva división sexual del trabajo en público/privado.

Mientras que el primero le queda asignado a los hombres, quienes trabajan en el ámbito público por un salario; las mujeres quedan confinadas al ámbito privado y son obligadas a 
realizar trabajo doméstico no remunerado -bajo el supuesto de su predisposición natural a tales actividades.

La nueva división sexual del trabajo diferenció no sólo las tareas que hombres y mujeres debían realizar, sino también sus experiencias, sus proyectos de vida, etc. En esta dirección, no debe pasarse por alto que para que tal confinamiento y reclusión fuera posible, ha sido fundamental la imposición de un discurso ideológico-discurso del Amo, del sistema simbólico de la cultura- encargado de interpelar a las mujeres para ocupar su lugar de madres, esposas, y amas de casa- en el que la culpa siempre ha jugado un rol fundamental (7).

En esta línea, uno de los principales mandatos de género era el que decretaba que el "matrimonio era la verdadera carrera para una mujer" (Federici, 2010: 120). A partir de ahora las mujeres debían obedecer al llamado de la interpelación ideológica para ocupar estos lugares que se les ha asignado previamente, ya que la "ideología está centrada y supone la existencia de un centro desde donde interpela y somete a los sujetos al Sujeto, en una doble relación especular" (Althusser, 2003: 52).

Tal interpelación fue efectiva en la medida que pudo reclutar a los sujetos femeninos y constituirlos como mujeres reproductoras, por un lado; y mujeres no trabajadoras, por otro (6). En este escenario quienes se animaban a trabajar fuera de sus casas eran consideradas "brujas" y "arpías" que intentaban subvertir el orden establecido. Uno de los pocos trabajos que podían realizar estas mujeres desobedientes era la prostitución. En realidad, se constituían en prostitutas y sirvientas a la vez, ya que "por más empobrecidos y carentes de poder que estuvieran los trabajadores varones, todavía podían beneficiarse del trabajo o del ingreso de sus esposas, o acudir a una prostituta" (Federici, 2010: 178). Simultáneamente, se legalizó la violación "lo que creó un clima intensamente misógino que degradó a todas las mujeres cualquiera que fuera su clase" pues "una vez violadas no les era fácil recuperar su lugar en la sociedad" (Ibídem: 92).

De esta manera, los cuerpos femeninos se constituyeron en cuerpos expropiables como las tierras colonizadas y en mercancías disponibles para el consumo. De allí que podamos afirmar con Federici que en el marco de las sociedades capitalistas, "el cuerpo es para las mujeres lo que la fábrica es para los trabajadores asalariados varones: el principal terreno de su explotación" (Ibídem: 28). A esto hay que agregarle, que en un sistema donde la vida está subordinada a la producción de ganancias, la acumulación de la fuerza de trabajo sólo puede lograrse con el máximo de violencia, para que la violencia misma se transforme en la fuerza más productiva. Es por ello que en el análisis de Federici existe una distancia con el análisis de Marx ya que la autora advierte que cada fase de la globalización "ha venido acompañada de un retorno a los aspectos más violentos de la acumulación originaria" (Ibídem: 30 ).

Ahora bien, una vez exploradas algunas ideas que se materializan en prácticas concretas de dominación, estamos en condiciones de afirmar que la dicotomía entre teoría y práctica, entre 
pensamiento y materia, entre idea y acción se desmorona al considerar que históricamente las construcciones discursivas han ido acompañadas de prácticas concretas insertas en la materialidad más cotidiana (8). ¿Qué es, sino, lo que ocurre cuando se afirma que "los inmigrantes quitan puestos de trabajo"? ¿O cuando se ejerce violencia institucional contra los "pibes chorros" bajo presunción de culpabilidad por "portación de rostro"? ¿Y cuándo se detiene a un "indio" por supuesto enriquecimiento ilícito?

La identificación de determinadas subjetividades con la naturaleza, con la materia, con "lo más bajo" ha dado lugar a que sean comprendidas como lo "otro" dicotómico. Ésta es la base sobre la cual se ha consolidado un discurso que demoniza y degrada a los cuerpos femeninos y a los cuerpos disidentes en términos de elección sexual, pertenencia étnico-racial y de clase. Lo cual explica el redisciplinamiento contra los cuerpos rebeldes, subversivos, resistentes: la esposa desobediente, la que decide abortar, la socorrista, la solterona, la que rompe con los mandatos que debería respetar (de maternidad, heteronormatividad, femineidad) la combativa, la bruja. Que debían ser doblegadas mediante violencia radical.

A propósito de cómo las mujeres deberían subordinarse a las decisiones que benefician y privilegian a los varones blancos, heterosexuales, de clase media o alta, es sintomático que pongamos en escena lo ocurrido el 28 de enero de 2017 en Necochea, provincia de Buenos Aires, cuando la policía montó un operativo con varios patrulleros, casi veinte oficiales y amenazas para expulsar a tres mujeres que hacian "topless" en la playa. Creemos que es importante vincular este acontecimiento porque revela cómo operan las violencias simbólica y real para domesticar a los cuerpos femeninos y disidentes; y manifiesta la ideología capitalista patriarcal en la que cada acción relacionada con el cuerpo, con el sexo, con el placer, para ser permitida, avalada y promocionada, debe estar orientada a la satisfacción masculina (9).

La radicalidad de la violencia material y simbólica ejercida contra aquellos que representan un peligro para el orden social explica la centralidad que tiene en este esquema la desmembración de los lazos sociales para poder conquistar estos cuerpos-territorios; para domesticar la comunidad y para encausar a los disidentes.

Es fundamental atender aquí a aquello que destaca Federici al sostener que uno de los discursos predilectos de las políticas oficiales de las colonias españolas- en las que la "raza" era el factor a partir del cual se ordenaba jerárquicamente la estructura social- era "Divide y reinarás" (2010: 196) bajo el cual se intenta romper todo tipo de alianzas que existía concretamente entre las mujeres más allá de su pertenencia étnico- racial.

A causa de la gran movilidad migratoria en la América hispana, se torna muy complicado para los colones jerarquizar de acuerdo a la racialización. $Y$ lo que ocurre además es que por entonces comienza a formarse "un proletariado urbano blanco sin perspectivas de mejora económica y, por lo tanto, propenso a identificarse con los mestizos y mulatos más que con los blancos de clase alta" (Ídem). Por ello, la Inquisición en el siglo XVIII en México tuvo que 
desistir a su plan de erradicar las creencias mágicas y heréticas (Federici, 2010: 197) ya que era imposible detener "los múltiples intercambios entre mujeres en temas relacionados con saberes ancestrales y curas mágicas para la salud, el amor y la abundancia". Tal como da cuenta la siguiente cita:

\begin{abstract}
Las mujeres indias daban colibríes a las curanderas españolas para que los usaran para la atracción sexual, las mulatas enseñaron a las mestizas a domesticar a sus maridos, una hechicera loba contó sobre el Demonio a una coyota. Este sistema "popular" de creencias era paralelo al sistema de creencias de la Iglesia y se propagó tan rápidamente como el cristianismo por el Nuevo Mundo, de tal manera que después de un tiempo se hizo imposible distinguir qué era "indio" y qué era "español" o "africano (Ídem).
\end{abstract}

La partición de lazos sociales puede ser pensada bajo la categoría de epistemicidio sexo genérico (Santos, 2010) en tanto destruyó un mundo de prácticas y saberes ancestrales que constituía el empoderamiento de las mujeres (10). Lo cual significó también la destrucción de la vida comunal dictada por el interés económico específico de asegurar las condiciones para una economía capitalista, para lo cual la reclusión forzosa de las mujeres a las actividades domésticas, fue fundamental para concretar este objetivo del sistema capitalista.

En este sentido, tanto como la "raza" la pertenencia sexual fue un factor de discriminación, que requirió formas específicas de violencia para lograr la domesticación de cuerpos rebeldes ("la esposa desobediente", la "gruñona", "la puta", "la curandera"). En las colonias españolas se dictaron leyes bajo las cuales las mujeres casadas se convirtieron en propiedad de los hombres y se creó todo un sistema de creencias y de valores -como el compadrazgo que le otorgaba mayor poder a los hombres sobre los niños- que limitaba aún más "el poder femenino". Para dar una muestra de la pérdida gradual de autonomía y de poder social que sufrieron las mujeres en este periodo.

Y que cobra total sentido al ser visto bajo la lupa que sugiere la lectura de Las estructuras elementales de la violencia de Rita Segato (2003) en la que se sostiene que las sociedades patriarcales de la modernidad colonial están estructuradas a partir del despojo del poder femenino por parte de los sujetos masculinos y del Estado de clases, lo cual requiere de la violencia como elemento central para estructurar ese dominio de lo masculino sobre to femenino y de la desigualdad entre estos términos.

A partir de lo cual se puede afirmar que el disciplinamiento que intenta "encausar" a las mujeres en los roles socialmente establecidos es el mismo que opera detrás de todas las formas de violencia de género hasta la actualidad. $Y$ de los cuales, el peor acaso lo constituye la violencia 
sexual. Disciplinar, controlar, anulares el mensaje dirigido a las otras mujeres que observan aterrorizadas.

En este marco, las distintas formas de violencia de género no sólo buscan agredir el cuerpo de las mujeres, o humillar a los varones, tal como muestran algunos testimonios de ex detenidos en centros clandestinos de detención durante la última dictadura militar- en la que se pone de relieve que las mujeres somos un botín de guerra (Lewin y Wornat, 2014). Lo cual permite considerar que el cuerpo de las mujeres necesariamente ha sido un campo de batalla para los pueblos y para los masculinos que combaten entre sí, al decir de Segato (2016) "somos territorios aptos para ser expropiados", o más bien: "refeudalizados" (p. 21). Lo cual arroja una puntada para atar cabos respecto a la trata de personas, la esclavitud sexual y la prostitución infantil, que lejos de desaparecer, se acrecienta producto de la demanda cada vez más grande de clientes- consumidores de cuerpos femeninos (cuanto más jóvenes mejor) que circulan en circuitos clandestinos, aunque habituales (11). Esta oferta y esta demanda no tiene otro factor que la vulnerabilidad de estas niñas que quedan totalmente expuestas para ser apropiadas, consumidas, aniquiladas, humilladas.

En este sentido, nos resulta fundamental el análisis de Colette Guillaumin (Curiel y Falquet, 2005) quien advierte que los cuerpos de las mujeres son apropiados en las sociedades capitalistas e intercambiados como bienes. Lo cual nos aporta una buena razón para reconocer la naturaleza específica de la opresión de las mujeres en el marco del capitalismo patriarcal en el que las relaciones de clases de sexos y las relaciones de clase "comunes" emplean instrumentalidades que se emplean en tanto "cosas" (p. 37).

Efectivamente, Guillaumin realiza un aporte que es capital al mostrar que los discursos racistas producen "razas", junto con las construcciones simbólicas que definen sus características y que generó una serie de dicotomías conceptuales homologadas a sexo/raza. En esta dirección, pudo dar cuenta de las relaciones entre sexismo y racismo en los procesos de subordinación de las mujeres (aun blancas) que estaban naturalizados al punto de volverse invisibles (Delphy, 1985). Siguiendo esta perspectiva Guillaumin pudo concluir que es el efecto material de la palabra ("la teoría no es sólo un acto contestatario") el que define la dimensión material de las relaciones de apropiación ya que la idea de naturaleza es la que luego sirve para enmascarar las opresiones. De allí que la pensadora francesa rechace la idea de "naturaleza" desde investigaciones que sólo tienen como objeto de estudio la racialización de una población inmigrante determinada, por ejemplo; que impide pensar en las relaciones específicas constitutivas de las categorías racializadas, reduciendo así la complejidad de la opresión específica de las mujeres.

\section{Cuerpos "vacíos" que deben ser llenados}


Si Federici se pregunta: "¿por qué el capitalismo surge cuando esta guerra contra las mujeres se está llevando a cabo?" nosotros podemos renovar el interrogante desde nuestra actualidad y preguntar: ¿qué relación guarda la avanzada neoliberal y neoconservadora con la creciente ola de violencia contra las mujeres y contra los más vulnerables?; ¿Cuál es el lente desde el cual se "nos mira" cuando por ejemplo se afirma públicamente: "Cuando hay una nena adentro también es Ni una menos"? (12); ¿qué ideas subyacen cuando se afirma que "hay mujeres que merecen ser violadas" (13); ¿o cuando se afirma fehacientemente que "nos embarazamos para cobrar un subsidio"? (14). ¿Tienen estos discursos, efectos materiales?

Insistimos -a poco del día de la lucha mundial por el aborto legal, seguro y gratuito: ¿es válida la asimilación entre una mujer que aborta y un femicida? ¿Puede Esteban Bullrich -un hombre blanco, educado y burgués hablar de aborto desde su situación de privilegio? Lo cual se vincula con el hecho de que en nuestras sociedades las mujeres ya no tendremos un vínculo con nuestro cuerpo que no sea mediado por los sentidos producidos por el patriarcado "incluso sobre experiencias que sólo nosotras podemos definir como el orgasmo, la gestación, el parto, la menstruación, el amamantamiento, y por cierto, el aborto" (Maffia, 2009: 221).

Por último: ¿Cuál es la concepción sobre nuestro cuerpo que subyace en el "ahí adentro"?

La ambigüedad en el lenguaje del ex ministro -ambigüedad que operara anteriormente en el uso de la palabra "dirigencia" en vez de repudiar con todas las letras al régimen nazi- pone de manifiesto la concepción degradada del cuerpo- entendido como máquina disociada del alma: “¿será que nuestro cuerpo es como una botella que se destapa y se vacía?”; “¿Somos simples envases del patriarcado capitalista?", se preguntó enardecidamente Marta Dillon (15).

La concepción del cuerpo como "envase vacío" es la misma que subyace en la concepción cartesiana del cuerpo-separado del alma, y que como hemos intentando mostrar- ha servido para justificar la matanza de brujas, la conquista de cuerpos negros, mestizos, primitivos y bestiales; es la misma violencia que opera contra los cuerpos anormales, monstruosos y disidentes.

Los restos de la sociedad, envases vacíos desechables: los que no son productivos, los cuerpos enfermos, discapacitados, los cuerpos gordos, los cuerpos feos, los que se saltan la norma.

Toda esta violencia que estructura al sistema se descargará siempre contra el más débil, el más vulnerable, el "otro" sobre el que se cola la fisura, el hedor y la perversión del sistema.

Hoy, en un contexto de avanzada neoconservadora y de hostilidad neoliberal- es urgente abonar argumentos en un terreno tan disputado para combatir los discursos sexistas, racistas, homofóbicos, gordofóbicos; discursos capaces de librar una batalla cuerpo a cuerpo contra la alteridad. 


\section{Conclusiones}

Las ideas, las teorías y las construcciones discursivas han tenido históricamente efectos materiales y especialmente nocivos sobre la alteridad. Que las mujeres fueran consideradas inferiores a los hombres "por naturaleza" ("excesivamente emocionales y lujuriosas, incapaces de manejarse por sí mismas"), tuvo como reverso el disciplinamiento y la domesticación de sus cuerpos, su subjetividad, sus proyectos de vida.

Lo paradójico es que una vez instaurado el capitalismo, el discurso sobre las mujeres cambia. $\mathrm{Si}$ antes estas eran consideradas como irracionales y bestiales, a partir de entonces se las describe como "obedientes", "sumisas", "capaces de apaciguar a los hombres". Todo ello muestra la efectividad de los discursos de degradación social femenina para la domesticación. Y también revela que el proyecto político moderno apunta a destruir a las mujeres, dejarlas sin autonomía y sin poder social para poder acumular capital político, social y económico. Tal proyecto entonces, encarna opresión, violencia y sometimiento contra los otros, los que deben ser disciplinados, controlados y anulados.

Así las cosas, los cuerpos femeninos se constituyeron en cuerpos disponibles, pasibles de ser vulnerados, disciplinados de acuerdo a las necesidades del sistema capitalista. Lo cual requirió de mecanismos de control de la reproducción desde comienzos del capitalismo hasta el neoliberalismo más exacerbado de nuestro presente; en el que discursos moralizantes como el de Bullrich intentan persuadir que una mujer que aborta es una asesina.

En este sentido, no fue casual en el periodo de transición al capitalismo -que al mismo tiempo que la población caía y se formaba una ideología que ponía énfasis en la centralidad del trabajo en la vida económica, se introdujeran sanciones severas en los códigos legales europeos destinadas a castigar a las mujeres culpables de crímenes reproductivos. Como no puede ser pura coincidencia que en la actualidad la batalla desatada por los "voceros del proyecto histórico del capital" -al decir de Segato- despliegue un discurso moral para controlar los cuerpos femeninos, postulando un retorno conservador del discurso moral sobre todo cristiano como el que encontramos por ejemplo en la destitución de Dilma Roussef en Brasil en "nombre de Dios" o "por el bien de la familia".

En definitiva: el análisis comparativo entre la caza de brujas en el medioevo y la guerra actual contra las mujeres revela que la violencia patriarcal -misógina, racista y homofóbica de la modernidad tardía arrasa sin freno sobre los cuerpos disidentes, los cuerpos rebeldes, los cuerpos negros, anormales, los no productivos, pobres y discapacitados.

Para finalizar, que un funcionario público se anime a decir -provocativamente- que las mujeres que abortan son tan asesinas como los femicidas, cuando cada 18 horas a una de nosotras se nos arrebatada la vida (o cuando dice sin titubeos que la bonaerense hace las cosas bien 
porque todos los días mete preso a un pibe) constituye la medida que marca una nueva forma de señorío -de "dueñidad" de nuestros cuerpos, resultante de la aceleración de la concentración de capital, de la crisis global y de la expansión de una esfera de control de la vida, que se sirve de los discursos morales como instrumentos de disciplinamiento. Hasta que no demos una batalla de ideas capaz de erradicar el patriarcado, el aborto legal seguirá siendo una deuda de nuestras sociedades democráticas y seguirá cobrándose la vida de las mujeres (principalmente de sectores más vulnerables) y la violencia de género nos seguirá matando cada día.

Para tal erradicación no podemos dejar de reconocer la dimensión ideológica- discursiva de toda relación social, es decir, el carácter material de las construcciones ideológicas cuyas consecuencias en las prácticas concretas se legitiman y se enmascaran a partir de estas mismas ideas.

Por todo ello la crítica filosófica, la crítica radical, la crítica incansable es hoy, más urgente que nunca, a pesar de que los ataques a las disciplinas sociales y humanas intenten convencernos de su caducidad. Pues, precisamente en este contexto de avanzada neoliberal podemos entender la amenaza que puede significar para los voceros del capital y para los guardianes de la buena moral, la argumentación, la deconstrucción de supuestos y las desnaturalizaciones.

Si Althusser está en lo cierto al sostener que lo importante de la filosofía es su posición y su intervención política en el campo de batalla; más que nunca entonces, urge promover estas discusiones por todos los frentes y circunstancias posibles- entendiendo que las ideas siempre se traducen en actos; que ningún discurso es inocente sino que sus efectos son tan materiales como el sistema que oprime, ya que "todo acontecimiento es un acontecimiento discursivo".

\section{Notas}

(1) El "otro" es una alteridad simbólica y material en términos de pertenencia étnico-cultural, de género y de clase. La alteridad se constituye en oposición a lo que no es Uno, al Otro del Sujeto universal del capitalismo desde los patrones del patriarcado colonial moderno: pobres, negros, indios, travestis, mujeres, niños, trans, lesbianas, etcétera que deberán ser "borrados", suprimidos, anulados.

(2) Desde una perspectiva lacaniana, el sujeto necesita del poder para relacionarse con las cosas, existe una relación posesiva con las cosas. En esta línea, el "yo" occidental es una forma de poder, no trascendental, sino construida sobre una relación de poder. J. Lacan, Seminario VII "La ética del psicoanálisis”, clase del 11 de mayo de 1960.

(3) Como bien muestra Quijano, la "raza" fue una invención que sirvió como instrumento para la transmisión de propiedad y para el funcionamiento de una jerarquía racial que separa a indígenas, mestizos, mulatos y la propia población blanca. De modo que bajo este análisis se puede ver "la fusión de las experiencias del colonialismo y la colonialidad con las necesidades del capitalismo, creando un universo específico de relaciones intersubjetivas de dominación bajo una hegemonía eurocentrada" (2002: 343). 
(4) La lectura sintomática es lo que Louis Althusser señala como lo contrario a una lectura ingenua, literal, y que él propone realizar a propósito de la obra de Marx, principalmente de El Capital, justamente en su obra Para leer El Capital de 1965. En este sentido, la lectura tiene el estatuto de práctica, de intervención. Ver Althusser, 2010.

(5) A partir de la propuesta de Sandra Harding (1991) y de Donna Haraway (1995) por ejemplo, se propone, ante el objetivismo de la ciencia positiva, reconocer "la parcialidad como nueva objetividad". De manera que "todo conocimiento humano está situado, toda visión del mundo está inevitablemente conformada por las experiencias y vidas de sus productores". (Pérez Orozco, 2014: 70-71). A propósito de la interseccionalidad sexo-género; clase y étnico-racial, ver "la separación categorial de raza, género, clase y sexualidad es una separación que no nos deja ver la violencia claramente. No se trata solamente de una cuestión de ceguera epistemológica, cuyo origen se radica en una separación categorial" (Lugones, 2008: 76).

(6) Es sumamente revelado en este sentido, poner de manifiesto como lo hacen Lewin y Wornat (2013) que si el trato con los varones era de humillación y sometimiento, pero de "igual a igual"; las violaciones sexuales contra las mujeres constituyeron las estrategias de aniquilamiento que el aparato ideológico de la dictadura militar utilizó para someter y degradar a las detenidas de forma radical: con el propósito de des-humanizarlas y aniquilarlas como sujetos. La insistencia de esta estrategia, pone de manifiesto que la violencia de género ha formado parte histórica y sistemáticamente de una estrategia de aniquilamiento de las mujeres como sujetos por parte del proyecto político patriarcal.

(7) Para Judith Butler existe una ambivalencia constitutiva del sujeto y de la forma mecánica del poder (1997) y además, afirma que la el sujeto y la identidad son construidos discursivamente: teoría performativa del discurso (2010).

(8) Desde una perspectiva materialista simbólica se afirma que el discurso del otro, cuya estructura se despliega en todo lo que nos rodea, es la exterioridad donde se realiza el trabajo del inconsciente y donde nos alienamos al identificarnos con el significante amo. "La materialidad simbólica sobre la que trabajamos, que forma parte del mismo sistema que nos explota y en la que se funda la dignidad por la que mi trabajo intelectual se distinguiría falsamente del trabajo manual" (Pavón Cuellar, 2014: 29).

(9) Una de las tantas notas al respecto, disponible online en: https://www.pagina12.com.ar/17138-se-viene-el-operativotetas-al-sol.

(10) El estatuto de epistemicidio sexo genérico puede ser ilustrado a partir de la discriminación que sufrieron las brujas y curanderas, mientras que las prácticas de los magos varones se mantuvieron impolutas. En esta misma dirección, a partir del siglo XVI el Estado comenzó a intentar quebrar el control que hasta entonces las mujeres habían tenido sobre su cuerpo, imponiendo penas severas a la anticoncepción, el aborto y el infanticidio, siendo a causa de esta última que las mujeres fueron ejecutadas en grandes cantidades más que de cualquier otro crimen (Federici, 2010: 159). La acusación de brujas y asesinas de niños también recayó sobre las parteras- "que condujo a la entrada del doctor (varón) en la sala de partos" (Ibídem: 160). Otra muestra del progresivo poder que las mujeres fueron perdiendo sobre sus proyectos de vida lo muestra la siguiente cita: “En México y Perú, donde la disminución de la población aconsejaba incentivar el trabajo doméstico femenino, las autoridades españolas introdujeron una nueva jerarquía sexual que privó a las mujeres indígenas de su autonomía y le otorgó a sus parientes de sexo masculino más poder sobre ellas" (Federici, 2010: 197).

(11) Para ampliar, ver nota reciente a propósito de la esclavitud sexual en Salta: http://vove.com.ar/noticia/404/loscaballeros-las-prefieren-ninas.

(12) Declaración ex ministro Esteban Bullrich, 31 de julio de 2017. Recuperado y disponible online:

https://www.pagina12.com.ar/53586-si-es-una-beba-ni-una-menos.

(13) Entrevista a Gustavo Cordera realizada por estudiantes de periodism. 10 de septiembre de 2016. Recuperada y disponible online: https:/www.infobae.com/sociedad/2016/08/10/gustavo-cordera-hay-mujeres-que-necesitan-servioladas-para-tener-sexo/.

(14) Lucía Galán en entrevista del 24 de julio de 2017. Recuperado y disponible online: http://www.eldia.com/nota/20177-25-2-10-53--hay-mujeres-que-tienen-hijos-por-el-subsidio--. 
(15) Dillon, Marta. El aborto legal, una deuda de la democracia. Envases del Patriarcado en Revista Anfibia, agosto del 2017. Disponible online: http://www.revistaanfibia.com/cronica/envases-del-patriarcado/\#sthash.GNW1cRxE.gbpl.

\section{Bibliografía}

Althusser, L. (2010). Prefacio. Para leer el Capital. Buenos Aires: Siglo XXI editores.

Althusser, L. (1988). Ideología y aparatos ideológicos del Estado. Buenos Aires: Nueva Visión.

Balibar, E. y Wallerstein, I. (1998). Raza, Nación y clase. Madrid: lepala.

Butler, J. (1997). Mecanismos psíquicos del poder. Madrid: editorial Cátedra.

Butler, J. (2010). El género en disputa. Barcelona: Paidós.

Curiel, O. y Falquet, J. (2005). El patriarcado al desnudo. Tres feministas materialistas: Colette Guillaumin-Paola Tabet-Nicole Claude Mathieu. Buenos Aires: Brecha lésbica ediciones.

Delphy, Ch. (1985). Por un feminismo materialista. El enemigo principal y otros textos. Cuadernos inacabados 2.3, Barcelona, La Sal ediciones de les dones.

Federici, S. (2010). El Calibán y la bruja. Mujeres, cuerpo y acumulación originaria. Tinta Limón Ediciones: Buenos Aires.

Femenías, M. L. (2008). Identidades esencializadas/violencias activadas. Isegoría. Revista de Filosofía Moral y Política, 38, pp. 15-38.

Foucault, M. (1975). Vigilar y castigar. Buenos Aires: Siglo XXI.

Foucault, M. (1976). Historia de la sexualidad. La voluntad del saber. Buenos Aires: Siglo XXI.

Gramsci, A. (1971). El materialismo histórico y la filosofía de Benedetto Croce. Buenos Aires: Ediciones Nueva Visión.

Grosfoguel, R. (julio-diciembre 2013). Racismo/sexismo epistémico, universidades occidentalizadas y los cuatro genocidios/epistemicidios del largo siglo XVI en Tabula Rasa. Bogotá, Colombia, 19, pp. 31-58.

Haraway, D. (1995). Ciencia, cyborgs y mujeres. La reinvención de la naturaleza. Madrid: Ediciones Cátedra.

Kójeve, A. (1982). La dialéctica del amo y del esclavo en Hegel. Buenos Aires: La Pléyade.

Lugones, M. (2008). Colonialidad y género: Hacia un feminismo descolonial. En Mignolo, W. (Comp.). Género y descolonialidad. Buenos Aires: Ediciones del Signo.

Lugones, M. (2012). Subjetividad esclava, colonialidad de género, marginalidad y opresiones múltiples. En Pensando los feminismos en Bolivia. La Paz: Conexión Fondo de Emancipaciones.

Maffía, D. (2007) Epistemología feminista: La subversión semiótica de las mujeres en la ciencia en Revista Venezolana de Estudios de la Mujer, 12(28), Caracas. Recuperado de http://www.scielo.org.ve/scielo.php?script=sci_arttext\&pid=S1316-37012007000100005 
Marx, K. (1984). Manuscritos económicos-filosóficos de 1844. Economía política y Filosofía. Buenos Aires: Cartago.

Marx, K. (2001). El Capital. Crítica de la Economía política. México: FCE.

Pavón Cuellar, D. (2014). Elementos políticos del marxismo lacaniano. Ciudad de México: Paradiso editores.

Pérez Orozco, A. (2014). Subversión feminista de la economía. Madrid: Traficantes de sueños.

Quijano, A. (2002). Colonialidad del poder, eurocentrismo y América Latina. En Edgardo Lander (comp.). Colonialidad del saber, eurocentrismo y ciencias sociales. Buenos Aires: CLACSO-UNESCO.

Santos, B. (2010). Para descolonizar Occidente. Buenos Aires: CLACSO.

Sciortino, S. (2014). Antropología y feminismos en América Latina: hacia una práctica descolonial. En Teoría feminista y Antropología: Claves Analíticas. Madrid: Centro de estudios Ramón Areces.

Segato, R. (2003). Las estructuras elementales de la violencia. Buenos Aires: Prometeo.

Segato, R. (2016). La guerra contra las mujeres. Buenos Aires: Tinta Limón.

Spivak, G. (1988). ¿Puede el sujeto subalterno hablar? Revista Colombiana de Antropología, 39, enero-diciembre, pp. 297-364. 